\title{
Acquisition of regional and cellular identities in the developing zebrafish nervous system
}

\author{
Stephen W. Wilson and Stephen S. Easter Jr
}

\author{
University of Michigan, Ann Arbor, Michigan, USA
}

\begin{abstract}
In the past year, several new techniques have been used with great success in the study of nervous system development in the zebrafish. Perhaps the most exciting results have come from experiments in which single identified cells or small groups of cells have been transplanted between embryos in order to examine cell determination and the site of action of genetic mutations.
\end{abstract}

Current Opinion in Neurobiology 1992, 2:9-15

\section{Introduction}

In recent years, the zebrafish embryo has become increasingly important for studies of nervous system de velopment $\left[1^{\bullet}\right]$. This review will summarize recent re search that has furthered our understanding of the de velopment, differentiation and patterning of neurons in the embryonic zebrafish nervous system. We will begin by reviewing the literature examining the role that lineage and cell position have to play in the specification of cell fate and then go on to discuss the concept of primary and secondary neurons in the nervous system, the possible functional roles played by early differentiated cells, how patterns of gene expression correlate with the regional subdivision of the nervous system, and current work on segmental patterning of cells in the nervous system. Other reviews (see $M$ Westerfield, pp 28-30, and J Kuwada, pp 31-35, this issue) discuss the mechanisms that might underlie pathfinding by growth cones of early neurons.

Small size and optical clarity are two of the major reasons why the zebrafish embryo lends itself to embryological study. These features mean that every cell in the developing nervous system is visible in an intact living embryo. Indeed, many neurons within the developing nervous system can be identified simply by their size, shape and location (for an example, see [2]). Not all developing cells can be distinguished this way, however, and a number of markers have proven useful for identifying different cell types.

The earliest marker of differentiating cells so far identified is acetylcholinesterase (AChE) activity [3,4*]. AChE is probably transiently present in all differentiating neurons and is not indicative of the neurotransmitter that will eventually be present in the cell [5]. The presence of AChE in a neuron precedes axogenesis by several hours.

A number of antibodies have also proven useful as markers of differentiation. The HNK-1 antibody labels an epitope present on several cell adhesion molecules [6] and has been used to visualize early neurons and their axons $[4 \bullet, 7,8 \bullet, 9]$. An antibody to acetylated $\alpha$-tubulin [10] labels most, if not all, axons in the early central nervous system (CNS) [11]. In addition, a large number of monoclonal antibodies against nervous system epitopes have been generated by researchers at the Institute for Neuroscience in Oregon. These antibodies recognize a variety of cell types in the nervous system including neuronal cell bodies, axons, cell nuclei, glial cells [12], and photoreceptors (S Wilson and S Easter, unpublished data; [13•]). Antibodies against intermediate filament epitopes can be used to identify very early populations of non-neuronal cells in the nervous system (R Marcus and S Easter, unpublished data).

The small size of the zebrafish embryo and the ease of accessibility of the nervous system allow single and small clusters of cells to be labelled with neuroanatomical tracers or fluorescent dyes both in living and fixed tissue (for examples, see $\left[2,9,14^{\bullet}\right]$ ). Using a combination of all of these various cell marking techniques, a fairly detailed knowledge has emerged of the patterns of early cellular differentiation in the embryonic zebrafish nervous system.

\section{Lineage and position as determinants of cellular identity}

Cell lineage in the embryonic zebrafish is indeterminate $[15,16]$. At early developmental stages the progeny of any one cell can give rise to many different cell types. It is only towards the end of the blastula stage that cell lineages within the deeper germ layers start to become restricted (Fig. $1 ;[17,18]$ ). Most cells undergo a single division during the late blastula stage that generates cells whose lineages are then tissue-restricted. It is at this stage that cells that give rise solely to nervous tissue are generated. The location of such cells during gastrulation predicts where the cells' progeny will end up within the nervous system. The most rostral parts of the CNS arise from dorsal regions near the animal pole, and more caudal CNS

\footnotetext{
Abbreviations

AChE - acetylcholinesterase; CNS - central nervous system.
} 
derives from marginal cells of the early gastrula. Interestingly, sensory neurons that are present in the dorsal CNS arise from ventral gastrula cells, whereas ventrally located motor neurons arise from the dorsal side of the gastrula. Although cells become restricted to the CNS during gastrulation, a single cell can still give rise to different neuronal types. It is therefore believed that the location at which a cell ends up within the CNS may play a more important role in determining the cell's fate than the cell's direct ancestry.

The importance of location upon cell identity has been tested directly by Eisen [19**]. By transplanting identified motor neurons between embryos at different devel. opmental stages Eisen has shown that cells transplanted about $1 \mathrm{~h}$ prior to axogenesis develop axons appropriate to their original location, and independent of their transplanted location. This indicates that, at this stage, the motor neurons are determined to adopt a particular fate If these same cells are transplanted at earlier developmen tal stages then they develop an identity appropriate to their new position, i.e. their fate is not determined at the time of transplantation, rather it is imposed upon the cell, dependent upon its location in the spinal cord.

The identity of at least one class of cell within the CNS may be under the control of a mesodermally derived signal. Cells of the midline floorplate do not differentiate in the cyclops $(c y c-1)$ mutation [20••]. The presence of wild type mesoderm transplanted into mutant embryos does not rescue the phenotype indicating that the $c y c$ 1 mutation acts autonomously in the ectoderm. If wild type cells are transplanted into mutant embryos and incorporated into the ventral CNS, however, they give rise to phenotypically normal floorplate cells. Indeed, when wild type cells do form floorplate in mutant embryos, they induce neighbouring mutant cells to do so as well - showing that mutant cells can differentiate into floorplate. The most simple explanation for these results is that floorplate can be induced via two pathways, the first from underlying notochord is blocked by the $c y c-1 \mathrm{mu}$ tation, and the second, between adjacent floorplate cells,

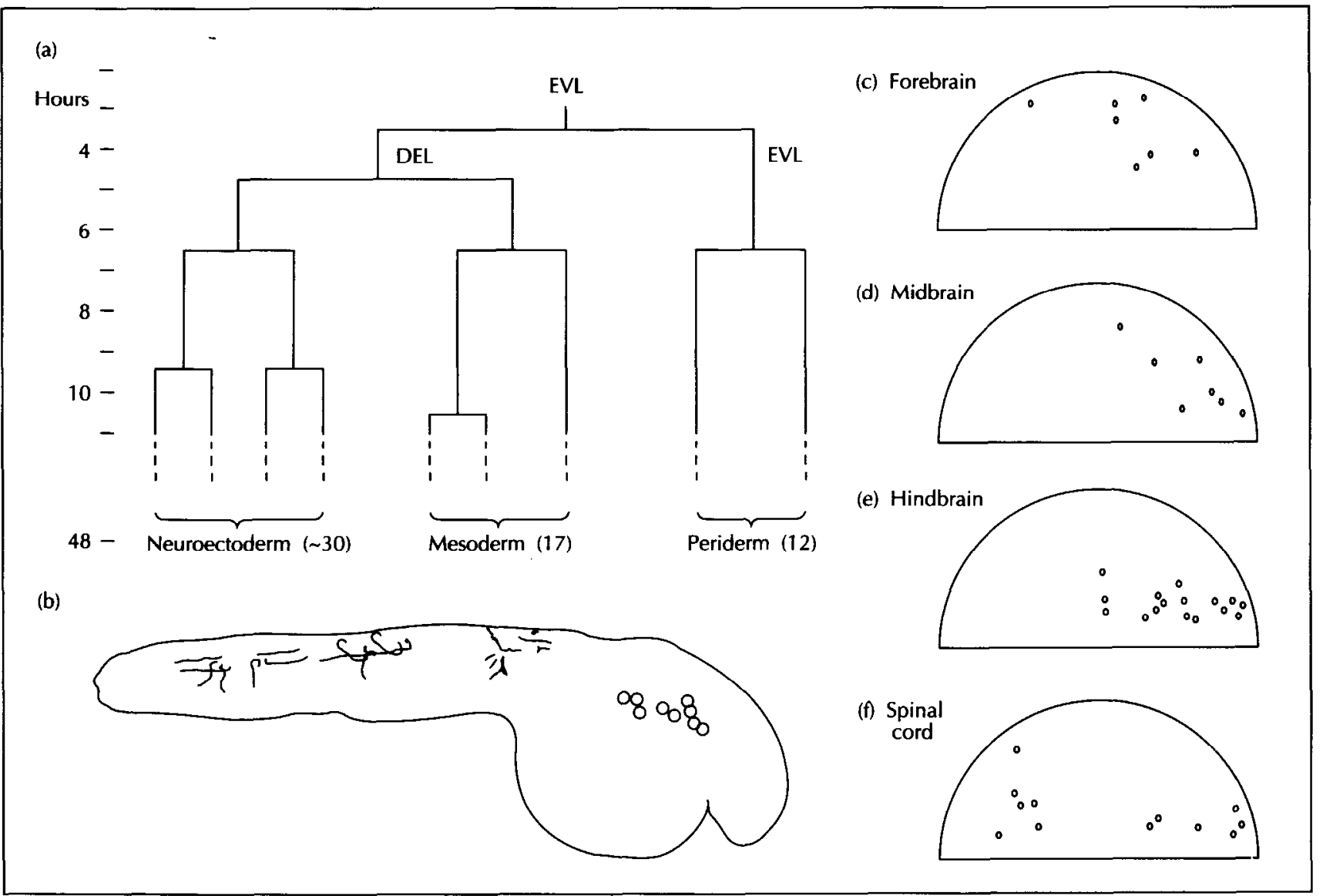

Fig. 1. Segregation of tissue-specific lineages in the blastula. (a) A lineage diagram beginning with an injected enveloping layer (EVL) cell, and showing numbers (in parentheses) and fates of its EVL and deep layer (DEL) descendants. Vertical lines represent cells and horizontal lines divisions. The time after fertilization is shown on the left of the diagram. The lineage was obtained from a video time lapse recording of the clone developing in the intact embryo. The recording interval ended at $11 \mathrm{~h}$. (b) A view of the same clone in the live embryo (right side with dorsal to the top) at $24 \mathrm{~h}$, drawn from the face of the video monitor. The three clusters of labelled cells are of three different tissue types, neuroectoderm, mesoderm and periderm, respectively. (c-f) Fate map positions of derivatives of the ectoderm. The outline represents a surface view of the left side of the blastoderm at $50 \%$ epiboly. Each point represents the blastoderm position of a single cell that was injected with lineage tracer in a separate embryo. The forebrain map (c) includes neural retina. Reproduced with permission from [18]. 
is normal in $c y c$-1. The remainder of the cell types in the spinal cord of this mutant appear normal ( $R$ Bernhardt and J Kuwada, personal communication; [20*•]) which suggests that it is unlikely that they depend on signals from the floorplate for their differentiation (see J Dodd, pp 3-8, this issue, for a more detailed discussion).

\section{Primary and secondary neurons}

There is strong evidence that many of the earliest neurons to develop in the zebrafish CNS are a distinct population [21•]. These neurons have been termed 'primary', a term that implies more than just their early appearance. Primary neurons are distinguished from later, secondary, neurons by their small number, large size, and their role in pioneering axonal pathways. The best characterized populations of primary and secondary neurons are present in the hindbrain and spinal cord. Cells that are classified as primary include three identified spinal motor neurons [2], Rohon-Beard cells and trigeminal sensory neurons [8*], reticulospinal neurons including the Mauthner cell [22], lateral line neurons [23], and at least one class of spinal cord interneuron [14*]. Some primary neurons persist in adulthood [24,25].

Whether neurons in more rostral brain regions can also be subdivided into primary and secondary populations is less clear. The early rostral brain is composed of a small number of neurons in predictable locations and these neurons establish a simple scaffold of axon tracts $[9,11]$. As yet, no study has examined the birthdates of neurons in this region of the CNS to see if they are born in an early primary and later secondary wave. There is evidence to suggest that some of the early brain nuclei do not conform to the primary and secondary divisions. Using markers of cellular differentiation, Ross et al. [4•] have shown that although the earliest brain nuclei do indeed initially contain a small number of differentiated cells, there is a subsequent linear increase (rather than two waves) in the numbcr of ncurons. At least some early brain neurons conform to many of the criteria used to classify primary neurons in other regions of the CNS, however. In the anlage of the epiphysis a single neuron develops very early and extends an axon that pioneers one of the earliest tracts in the brain [26•]. This neuron is the first of a small number of neurons that establish a projection between the epiphysis and the ventral diencephalon $[27 \bullet]$.

Grunwald et al. [28] have shown that a mutation termed ned 1 specifically causes secondary neurons to degenerate while primary neurons are spared. However, the effects of the mutation on rostral brain regions were not carefully examined in this study in which primary neurons were operationally defined as cells that elaborated an axon by $24 \mathrm{~h}$ post-fertilization. Kimmel and Westerfield [21•] acknowledge that this operational definition may be inappropriate for some regions of the nervous system and so more work must be done to clarify whether the primary/secondary distinction, with all of its implications, is generally valid in all regions of the CNS.

\section{Functional roles of early neurons}

There is a considerable amount of information about the functional circuitry of the early neurons of Xenopus laevis [29]. With a few exceptions, this is not the case for zebrafish. The best documented early circuitry is that associated with the Mauthner neuron $[21 \bullet, 30]$. This neuron receives sensory input from several sensory sources and has synaptic connections to primary motor neurons of the spinal cord. In the adult, this pathway evokes an escape reflex in response to touch [31] and so it is likely that a similar functional role is present during development.

Recent results have suggested that some of the neurons in the brain may be involved in early light-mediated behaviour. Long before an optic projection exists from the eyes to the tectum, there is a very early projection from the epiphysis to the ventral diencephalon [27•]. The epiphysial projection neurons that establish this projection are in close proximity to several early differentiating photoreceptor cells at the dorsal midline of the epiphysial vesicle (S Wilson and S Easter, unpublished data). The early differentiation of photoreceptors and projection neurons suggests that the epiphysis may mediate the earliest light-evoked behaviour in the embryo, as is the case in Xenopus [32]

The earliest neurons to differentiate may play additional roles during early CNS development. For instance, their axons establish the first long pathways in the CNS $[4 \bullet, 11,26 \bullet, 33,34]$, which provide an important substrate for the axons of many later developing neurons $\left[9,34,35^{\bullet}\right]$.

\section{Gene expression patterns in the central nervous system}

One of the ways in which the nervous system may become regionalized is through the differential expression of developmental control genes in different areas of the CNS. Several classes of developmentally regulated genes have been identified in the zebrafish through homology to known mammalian or Drosopbila genes. An advantage offered by the zebrafish for studies of gene expression is that the embryo is small enough to allow expression patterns to be examined in whole embryos, and localized to individual cells [36॰].

Homeobox-containing genes encode proteins that contain a domain that binds DNA. It is therefore believed that they may encode transcription factors. The zebrafish genome contains many different homeobox-containing genes $[37-42,43 \bullet, 44 \bullet, 45,46]$. Two engrailed-like genes have been identified [37], and antibodies that recognize the protein products of these genes have allowed expression patterns to be studied in detail $\left[42,43 \cdot, 44^{\bullet}\right]$. Within the CNS, engrailed-like antigens are expressed in a stripe that predicts the location of the future midbrain/hindbrain junction, and also within segmentally ar ranged cells of the hindbrain and intermediate zone cells of the spinal cord. Another homeobox gene, X1Hbox 1 , 
shows graded expression in a further class of spinal cord cells, the dorsally located Rohon-Beard sensory cells [45].

A second class of genes that may encode proteins that act as transcription factors are the paired box-containing or pax genes. The expression pattern of two pax genes in the zebrafish CNS : as recently been reported [36*]. In the CNS, $p a x(z f b)$ is expressed in the optic stalks, in a band of cells in the posterior midbrain, and in isolated cells of the spinal cord. $\operatorname{Pax}(z f a)$ has an even more intriguing expression pattern. It is expressed in a restricted region of the presumptive diencephalon and shows graded expression in the presumptive hindbrain and spinal cord. The diencephalic expression demarcates a region that may be bounded by some of the earliest axon tracts in the brain (Fig. 2), suggesting that the gene may be involved in specifying where the earliest axons will grow.
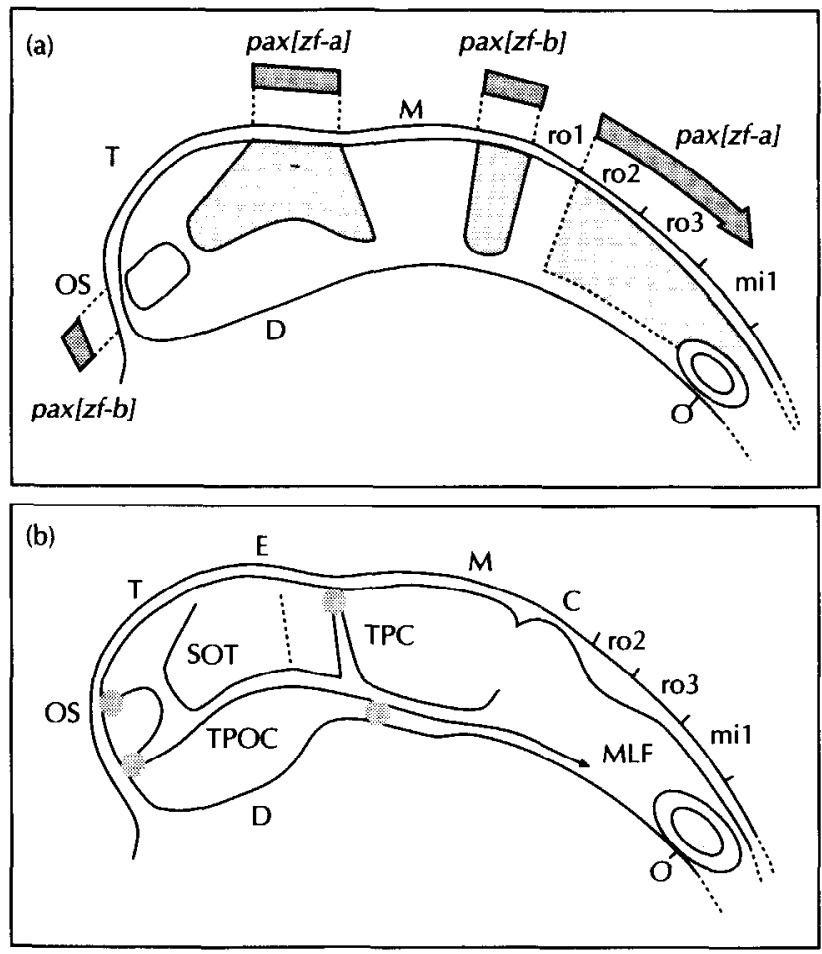

Fig. 2. A comparison of pax(zf) expression patterns and the organization of the initial scaffold of tracts in the rostral brain of zebrafish embryos. Rostral is to the left and dorsal is up. (a) A schematic drawing of the spatial distribution of pax $(z f-a)$ and pax $(z t-b)$ transcripts in the rostral region of an $18 \mathrm{~h}$ embryo. The shaded regions indicate the areas of expression at the surface of the developing brain. An unshaded area at the rostral end of the brain shows the location of pax (zf-b) transcripts in the base of the optic stalk. (b) A schematic drawing of the axon tracts present at 1 day of development. The stippled line marks the dorsoventral diencephalic tract. C, cerebellum. D, diencephalon. E, epiphysis. $M$, midbrain. MLF, medial longitudinal fasciculus. $O$, optic vesicle. OS, optic stalk. SOT, supraoptic tract. T, telencephalon. TPC, tract of the posterior commissure. TPOC, tract of the postoptic commissure. Commissures are represented as filled circles and the rhombomeres of the hindbrain are numbered (ro1, ro2, ro3, mi1). Reproduced with permission from $\left[9,36^{\bullet}\right]$.

It is not only putative transcription factor genes that are expressed in interesting patterns. The wnt 1 gene, which encodes a secretory protein that may be involved in local cell-cell signalling, also shows region specific expression in the CNS [47•]. It is expressed in the dorsal and lateral midbrain, and in the dorsal hindbrain and spinal cord. In Drasophila, the wingless gene product (homologous to the $w n t-1$ gene product) is necessary for maintaining expression of engrailed during development and thereby affects the specification of certain cell fates [48]. It remains to be seen if this gene plays similar roles in vertebrate development.

\section{Segmentation}

Segmentation is a feature of CNS development for which there may be different developmental programs in different regions of the CNS. Neurons may be intrinsically segmented, have segmentation imposed upon them extrinsically, or show no segmental patterning at all. The most obvious segmentation in the CNS is present in the hindbrain $[12,49]$ where seven segments, termed neuromeres or rhombomeres, containing a series of repeating features are found. The first basal plate neurons form in the centre of each neuromere and develop longitudi nal axons, whereas the first alar plate neurons develop around the segment boundaries and form ventral commissures. Glial cells are also arranged segmentally in this region of the brain. There have been no experiments to test whether hindbrain segmentation is intrinsic or extrinsic in zebrafish.

Some neurons are also arranged segmentally in the spinal cord. Each spinal hemisegment contains three or four identified motor neurons $[50,51]$ and may also contain one class of segmentally repeated interneuron $\left[14^{\bullet}\right]$. Two lines of evidence suggest that the segmentation seen in the spinal cord is imposed by the underlying mesoderm. The first comes from heat shock experiments which disrupt somite formation. In those regions where somites are disturbed, the pattern of the primary motor neurons is also disrupted [52]. The second comes from studies of the Spt-1 mutation which affects segmental organization of neurons. This mutation is cell autonomous and prevents normal migration of the mesodermal precursor cells that eventually form the segmented body wall of the embryo $\left[53,54^{\bullet} \cdot\right.$. Because of the cell autonomy of the mutation, any effects seen in the nervous system are due to a primary disruption of the mesodermal segmentation pattern. Eisen and Pike [55 ] found that the number of primary motor neurons and segmental interneurons corresponded with the number of myotomes that were present in the mutant embryo. Non-segmental neurons were unaffected by the mutation. Furthermore, wild type motor neurons transplanted into mutant embryos behaved in the same way as the native motor neurons, that is, their pattern of development was dictated by the mesoderm.

Once again, the situation with regard to segmentation in the rostral brain is less clear. Wilson et al. [9] concluded that by $24 \mathrm{~h}$ after fertilization there was no obvious pattern of segments to correspond with neuromeres seen in the hindbrain. Ross et al. [4॰] have examined the earliest neurons in the brain and found that initially there are three clusters of early differentiating cells, one in the dor- 
sal prosencephalon, one in the ventral prosencephalon and one in the ventral mesencephalon. The latter two clusters of neurons bear some degree of homology to the basal neurons in the rhombomeres of the hindbrain in that they contribute to the establishment of a longitudinal tract that links the forebrain to the spinal cord. The recent identification of regionally expressed genes in the rostral brain (S Krauss, personal communication; [21•]) should yield further information pertinent to the manner in which regionalization occurs in rostral regions of the brain.

\section{Perspectives}

The past few years have seen an explosion in the amount of scientific research that is being carried out on the zebrafish embryo. It is likely that this trend will continue for the foreseeable future as more techniques are developed, new mutations are generated, and researchers with new areas of expertise are drawn into the field.

There are now many groups examining the molecular and genetic mechanisms that underlie differentiation of the nervous system, and the potential exists for detailed examination of the patterns of neuronal development with respect to patterns of gene expression. Whole embryos can be double labelled with antibodies against specific cell types and either antibodies to specific gene products $\left[44^{\bullet}, 45\right]$ or specific cDNA probes (S Krauss and $\mathrm{S}$ Wilson, unpublished data). These techniques allow differentiation to be studied at the level of both the whole organism and the single cell within each experimental embryo. Furthermore, genetic manipulation is now feasible in the zebrafish embryo. Stuart et al. [56,57•] have shown that the zebrafish genome can incorporate and express foreign DNA. Such techniques should in the future allow manipulation of developmentally important genes through insertional mutagenesis.

Because of the ability to combine powerful cellular ma nipulation techniques with genetic and molecular methods, the zebrafish embryo offers many advantages for future studies of nervous system development.

\section{References and recommended reading}

Papers of particular interest, published within the annual period of re view, have been highlighted as:

- of special interest

-. of outstanding interest

1. EISEN J: Developmental Neurobiology of the Zebrafish. $J$ - Neurasci 1991, 11:311-317.

This is an excellent, fairly comprehensive review of the literature relating to all aspeçts of nervous system development in the zelorafish.

2. EISEN J, Myers PZ, Westerfield M: Pathway Selection by Growth Cones of Identified Motoneurons in Live Zebrafish Embryos. Nature 1986, 320:269-271.

3. Hanneman E, Westerfieid M: Early Expression of Acetylcholinesterase Activity in Functionally Distinct Neurons of the Zebrafish. J Comp Neurol 1989, 284:350-361.

4. ROSS L, ParretT T, EAster SS JR: Axonogenesis and Morpho- genesis in the Embryonic Zebrafish Brain. J Neurosci 1991 in press.

HNK-1 staining and AChE activity are used as markers of cellular dif ferentiation in this study which examines the very early morphogenesis of rostral brain regions. The relative positions of the early cell nuclei at different stages of development allow the authors to conclude that the ventral regions of the brain are originally located at the rostral end of the neural tube.

5. LAYER P: Comparative Localization of Acetylcholinesterase and Pseudocholinesterase During Morphogenesis of the Chicken Brain. Proc Natl Acad Sci USA 1983, 80:6413-6417.

6. Kruse J, Mailhammer R, Wernecke H, FaisSNer A, SOMmer I, GONDIS C, SCHACHNER M: Neural Cell Adhesion Molecules and Myelin-Associated Glycoprotein Share a Common Carbohydrate Moiety Recognised by Monoclonal Antibodies L2 and HNK-1. Nature 1984, 311:153-155.

7. NORDLANDER R: HNK-1 Marks Earliest Axonal Outgrowth in Xenopus. Dev Brain Res 1989, 50:147-153.

8. MeTCAlfe WK, MYers PZ, TReVarRow B, Bass MB, Kimmel CB:

- Primary Neurons that Express the L2/HNK-1 Carbohydrate During Early Development in the Zebrafish. Development 1990, 110:491-504.

Early sensory neurons in the nervous system include Rohon-Beard cells and trigeminal ganglion neurons. This study shows that both cell classes express the HNK-1 tetrasaccharide very strongly on their growth cones and axons. The axons of both classes of cell grow along the same central pathway where they fasciculate together. The authors suggest that the two cell classes share a common developmental program and that the HNK-1 epitope may be important in axonal growth and synaptogenesis.

9. WLSON SW, ROSS LS, ParRetT T, Easter SS JR: Development of a Simple Scaffold of Axon Tracts in the Brain of the Embryonic Zebrafish, Brachydanio Rerio. Development 1990 , 108:121-145.

10. PIPERNO G, FULLer MT: Monoclonal Antibodies Specific for an Acetylated Form of Alpha-Tubulin Recognize the Antigen in Cilia and Flagella from a Variety of Species. J Cell Biol 1985, 101:2085-2094.

11. ChITNIS AB, KuWADA JY: Axogenesis in the Brain of Zebrafish Embryos. J Neurosci 1990, 10:1892-1905.

12. Trevarrow B, Marks DL, Kimmel CB: Otganisation of Hindbrain Segments in the Zebrafish Embryo. Neuron 1990, 4:669-679

13. IARISON KD, Bremilier R: Early Onset of Phenotype and Cell

- Patterning in the Embryonic Zebrafish Retina. Development $1990,109: 567-576$.

The adult retina of the zebrafish, as is the case with many teleost fishes, contains cone photoreceptors organized in a simple pattern known as a cone mosaic. The study shows that this pattern of cones is present at early stages of retinal development. A monoclonal antibody, FRet 43, was used to study the appearance of the double cone class of photoreceptors. The appearance of FRet 43 antigenicity occurred within $3 \mathrm{~h}$ of the final mitosis giving rise to the photoreceptors. Mosaic patterning appeared within $6 \mathrm{~h}$ of the onset of FRet 43 antigenicity.

14. BERNHARDT RR, CHTTNS AB, LINDAMER L, KUWADA JY: Iden- tification of Spinal Neurons in the Embryonic and Larval Zebrafish. J Comp Neurol 1990, 302:603-616.

This study examines early neuronal development in the spinal cord us ing both intracellular and extracellular injections of neuroanatomical tracers. Nine classes of cells were identified, five of which were present at $18-20 \mathrm{~h}$ post fertilization.

15. KIMmEL CB, WARGA R: Indeterminate Cell Lineage of the Zebrafish Embryo. Dev Biol 1987, 124:269-280.

16. Streisinger G, Coale F, Taggert C, Waiker C, Grunwaid DJ: Clonal Origins of Cells in the Pigmented Retina of the Zebrafish Eye. Dev Biol 1990, 131:60-69.

17. KIMMfL CB, WARGA R: Tissue Specific Cell Lineages Originate in the Gastrula of the Zebrafish. Science 1986, 231:365-368.

18. KIMMEL CB, WARGA RM, SCHIJING TF: Origin and Organization of the Zebrafish Fate Map. Development 1990, 108:581-594. 
19. EISEN JS: Determination of Primary Motoneuron Identity in .. Developing Zebrafish Embryos. Science 1991, 252:569-572. Zebrafish primary motor neurons can be uniquely identified on the basis of their position in the spinal cord and their axonal projection pat terns. These features are used to determine whether individually trans planted motor neurons develop according to either their original, or their transplanted, position in the spinal cord. Using novel techniques, Eisen shows that motor neuron identity is determined by $1 \mathrm{~h}$ prior to axogenesis. Transplantations 2 or $3 \mathrm{~h}$ prior to axogenesis indicate that at these stages identity can be changed if the motor neurons occupy new locations in the cord.

20. HatTA K, Kimmel CB, Ho RK, Waiker C: The Cyclops Muta-. tion Blocks Specification of the Floor Plate of the Zebrafish Central Nervous System. Nature 1991, 350:339-341.

Embryos homozygous for the $c y c$-1 mutation lack a floorplate in their ventral CNS. Through elegant transplantation experiments that give rise to mosaic embryos the authors show that the $c y c-1$ mutation acts autonomously in the ectoderm. They demonstrate that wild type cells can form normal floorplate in mutant embryos, indicating that a floorplate induction signal is present.

21. KimMEL CB, WeSTERFIELD M: Primary Neurons of the Ze. - brafish. In Signal and Sense, edited by Edelman GM, Gall WE Cowan WM [book]. New York: Wiley Liss 1990, pp 561-588. This is a very comprehensive article that reviews most of the literature concerning primary and secondary neurons in the zebrafish nervous system. Sensory neurons, primary reticulospinal neurons and spinal motor ncurons arc discussed in detail.

22. Metcaife WK, MeNDeison B, Kimmel CB: Segmental Homologies Among Reticulospinal Neurons in the Hindbrain of the Zebrafish Larva. J Comp Neurol 1986, 251:147-159.

23. METCAIFE WK: Sensory Neuron Growth Cones Comigrate with Posterior Lateral Line Primordial Cells in Zebrafish. $J$ Comp Neurol 1985, 238:218-224.

24. WESTERFIELD M, MCMUJRAY JV, EISEN JS: Identified Motoneurons and Their Innervation of Axial Muscle in the Zebrafish J Neurasci 1986, 6:2267-2277.

25. LEE RK, EATON RC: Identifiable Reticulospinal Neurons of the Adult Zebrafish, Bracbydanio rerio. I Comp Neurol 1991, 304:34-52.

26. WiLSON SW, EASTer SS JR: A Pioneering Growth Cone in the - Embryonic Zebrafish Brain. Proc Natl Acad Sci USA 1991, 88:2293-2296.

This study describes the development of one of the earliest tracts in the brain, that from the epiphysis. Using a combination of neuroanatomical tracing techniques and electron microscopy, it is shown that the tract is pioneered by the growth cone of a single neuron.

27. WILSON SW, EASTER SS JR: Stereotyped Pathfinding by Growth - Cones of Early Epiphysial Neurons in the Embryonic Ze brafish. Development 1991, 112:121-145.

The first growth cone from the epiphysis pioneers one of the early brain tracts [26 $6^{\bullet}$. This study shows that the morphology of the leading epiphysial growth cone changes at different locations along its trajectory in response to changes in the local environment. Epiphysial growth cones encounter two regions in which they are faced with divergent axonal pathways; they invariably choose the appropriate path. Even growth cones that encounter a tract at an inappropriate location make correct pathfinding decisions. These results suggest that guidance cues are dis tributed throughout the scaffold of early brain tracts.

28. Grunwald DJ, Kimmel CB, Westerfield M, Waiker C, STREISINGER G: A Neural Degeneration Mutation that Spares Primary Neurons in the Zebrafish. Dev Biol 1988, 126:115-128

29. ROBERTS A: The Neurons that Control Axial Movements in a Frog Embryo. Am Zool 1989, 29:53-63.

30. Kimmel CB, Hatta K, MetCajfe W: Early Axonal Contacts During Development of an Identified Dendrite in the Brain of Zebrafish. Neuron 1990, 4:535-545

31. FETCHO JR, FABER DS: Identification of Motoneurons and Interneurons in the Spinal Network for Escapes Initiated by the Mauthner Cell in Goldfish. $J$ Neurasci 1988, 8:4192-4213.
32. ROBERTS A: Pineal Eye and Behaviour in Xenopus Tadpoles. Nature 1978, 273:774-775.

33. MENDEISON B: Development of Reticulospinal Neurons of the Zebrafish. II. Early Axonal Outgrowth and Cell Body Position. J Comp Neurol 1986, 251:172-184.

34. KUWADA JY: Cell Recognition by Neuronal Growth Cones in a Simple Vertebrate Embryo. Science 1986, 233:740-746.

35. CHITNS AB, KUWADA JY: Elimination of a Brain Tract In- creases Errors in Pathfinding by Follower Growth Cones in the Zebrafish Embryo. Neuron 1991, 7:277-285.

This paper follows up on earlier observations [11] that correct pathfinding by the growth cones of a cluster of midbrain neurons (nucPC) may be dependent upon axons from the diencephalon. In this study the authors transect the brain so that the link between diencephalon and midbrain is broken. In the absence of the diencephalic axons, the nucPC growth cones make more pathfinding errors.

36. Krauss S, Johansen T, Korza V, Fjose A: Expression Pattem - of Zebrafish pax Genes Suggests a Role in Early Brain Regionalization. Nature 1991, 353:267-270.

The rloning and expression patterns of two zebrafish paired box con taining genes are described. $\operatorname{Pax}(z f a)$ shows between $60 \%$ and $70 \%$ homology to the murine Pax 3 and $P a x 7$ genes, and $P a x(z f b)$ is nearly identical to mouse Pax2. The expression patterns of these genes are described using both conventional radio-labelled probes and digoxy. genin labelled probes on whole-mounted tissue. It is suggested that the genes may be involved in regionalization of the CNS, in particular, in determining the location at which the earliest brain tracts will form.

37. Fjose A, Eiken HG, NJolstad PR, Molven A, Horduvik I: A Zebrafish Engrailed-Like Homeobox Sequence Expressed During Embryogenesis. FEBS Lett 1988, 231:355-360.

38. NJOLSTAD PR, MOLVEN A, EIKEN HG, FJOSE A: Structure and Neural Expression of a Zebrafish Homeobox Sequence. Gene 1988, 73:33-46.

39. NJOISTAD PR, MOLven A, Fjose A: A Zebrafish Homologue of the Murine Hox-2 Gene. FEBS Lell 1988, 230:25-30.

40. NJOLSTAD PR, MOLVEn A, APOLD J, FJOSE A: The Zebrafish Homeobox Gene Hox-2.2: Transcription Unit, Potential Regulatory Regions and In Situ Localization of Transcripts. EMBO J 1990, 9:515-524.

41. AKIMENKO M-A, EKKER M, WESTERFIELD M: Characterization of Three Zebrafish Genes Related to Hox-7. In Developmental Patterning of the Vertebrate Limb, edited by Hinchcliffe JR, Hurle J, Summerball D [book]. New York: Plenum 1991, pp $61-63$.

42. Patel nh, martin-Blanco e, Coleman KG, Poole SJ, Elus MC, KORNBERG TB, GOODMAN CS: Expression of Engrailed Proteins in Arthropods, Annelids and Chordates. Cell 1989, 58:955-968.

43. HatTa K, SChILING TF, Bremiller R, Kimmel CB: Specifi- cation of Jaw Muscle Identity in Zebrafish: Correlation with Engrailed Homeoprotein Expression. Science 1990, 250:802-805.

Two functionally related head muscles transiently express engrailed homeodomain proteins from very early stages of their development. It is suggested that the engrailed proteins may establish muscle identity and be involved in neuromuscular target recognition.

44. Hatta K, Bremiller R, Westerfield M, Kimmel CB: Diversity - of Expression of Engrailed-Like Antigens in Zebrafish. De velopment 1991, 112:821-832.

Two antibodies are used to examine the developmental expression of engrailed like antigens. Each antibody shows different pattems of staining though many cell types are staincd by both. Expression is seen both within the brain and in the myotomes at locations where bound aries will later form. In a mutant in which myotomal boundaries are not present, there is a corresponding lack of engrailed-like expression. In addition to these boundary cells, engrailed-like antigen is expressed widely throughout different tissues of the embryo suggesting that it may play a role in both compartmentalization and in the formation of specialized structures 
45. MOLVEN A, WRIGHT CVE, BREMILLER R, DEROBERTTS EM, KIMMEL CB: Expression of a Homeobox Gene Product in Normal and Mutant Zebrafish Embryos: Evolution of the Tetrapod Body Plan. Development 1990, 109:279-288.

46. HOLAND PWH: Cloning and Evolutionary Analysis of MSHLike Homeobox Genes from Mouse, Zebrafish and Ascidian. Gene 1991, 98:253-258.

47. MOlven A, NJOLSIAU PR, FJuse A: Genomic Structure and - Restricted Neural Expression of the Zebrafish wnt-1 (int 1) Gene. EMBO J 1991, 10:799-807.

This study describes the molecular cloning and expression pattern of the zebrafish $w n t-1$ gene. The derived amino acid sequence of the gene product and the expression pattern of the gene are similar to those seen for the mouse Wnt-1 gene. Outside the coding regions of the gene there are no homologies between zebrafish and mice, however.

48. HeEmSKERK J, Dinardo S, KOSTRIKEN R, O'FARRELL PH: Multiple Modes of Engrailed Regulation in the Progression Towards Cell Fate Determination. Nature 1991, 352:404 410.

49. Hanneman E, Trevarrow B, Metcalfe WK, Kimmel. CB, Westerfield M: Segmental Pattern of Development of the Hindbrain and Spinal Cord of the Zebrafish Embryo. Devel. opment 1988, 103:49-58.

50. MYERS PZ, EISEN JS, WESTERFIELD M: Development and Axonal Outgrowth of Identified Motoneurons in the Zebrafish. $J$ Neurosci 1986, 6:2278-2289.

51. EISEN JS, PIKE SH, ROMANCIER B: An Identified Motoneuron with Variable Fates in Embryonic Zebrafish. I Neurasci 1990, 10:34-43.

52. KIMMEL CB, SEPICH DS, TREVARROW B: Development of Segmentation in Zebrafish. Development 1988, 104:(suppl) 197-207.

53. KIMMEL CB, KaNe DA, WAIKeR C, WARGA RM, ROTHMAN MB A Mutation that Changes Cell Movement and Cell Fate in the Zebrafish Embryo. Nature 1989, 337:358-362.

54. Ho RK, KANE DA: Cell Autonomous Action of Zebrafish Spt-. 1 Mutation in Specific Mesodermal Precursors. Nature 1990 , 348:728-730
The spadetail mutation is characterized by abnormal development of the trunk region of the embryo. This elegantly designed study shows that the mutant phenotype is a result of failure of specific mesodermal precursor cells to undergo one of the cell movements associated with gastrulation. The authors co-transplanted fluorescently labelled wild type and mutant cells to the marginal zone of wild type blastula stage embryos. In contrast to the transplanted wild type cells, the mutant cells all failed to converge dorsally and ended up in the tailbud.

55. EISEN JS, PIKE SH: The Spt-1 Mutation Alters Segmental Ar- rangement and Axonal Development of Identified Neurons in the Spinal Cord of the Embryonic Zebrafish. Neuron $1991,6: 767-776$

The authors examine the development of segmental and non-segmen. tal neurons of the spinal cord in the spadetail mutant. This mutation leads to abnormal formation of body wall muscle segments. They found that in regions where myotomes are disrupred, there is a correspond. ing disruption of segmentation in the spinal cord. Non-segmental spinal cord cells are unaffected by the mutation. The effect of the mutation was shown to be non-autonomous by transplanting wild type cells into mutant embryo spinal cords and observing disnuption of their development.

56. STUART GW, MCMURRAY JV, WESTERFIEID M: Rcplication, Intcgration and Stable Germ-Line Transmission of Foreign Sequences Injected Into Early Zebrafish Embryos. Develop ment 1988, 103:403 412.

57. STUART GW, VIELKIND JR, MCMURRAY JV, WESTERFIELD M: Sta- ble Lines of Transgenic Zebrafish Exhibit Reproducible Patterns of Transgene Expression. Development 1990, 109:577-584.

This study describes the generation of transgenic zebrafish through in. jection of plasmids containing both Rous sarcoma virus and SV40 promoter sequences upstream of a chloramphenicol acetyltransferase gene into a one cell embryo. Foreign DNA was incorporated into the germ line cells of approximately $5 \%$ of the injected fish. The progeny of these fish were fully hemizygous for the transgene marker, and showed consistent patterns of transgene expression in several different tissue types.

SW Wilson and SS Easter Jr, Department of Biology, University of Michigan, Ann Arbor, Michigan 48109, USA. 